\title{
PET monitoring of liver directed selective internal radionuclide therapy for metastatic gastro-oesophageal cancer
}

\author{
Dale L Bailey, ${ }^{1}$ Adrian Lee, ${ }^{2}$ Bob T Li, ${ }^{2,3}$ Stephen J Clarke ${ }^{2,4}$
}

'Department of Nuclear Medicine, Royal North Shore Hospital, New South Wales, Australia

${ }^{2}$ Sydney Medical School, University of Sydney, Australia ${ }^{3}$ Thoracic Oncology Service, Developmental Therapeutics Center, Memorial Sloan Kettering Cancer Center, New York, New York, USA ${ }^{4}$ Department of Medical Oncology, Royal North Shore Hospital, New South Wales, Australia

Correspondence to Dr Adrian Lee, adrian.lee@sydney.edu.au

Accepted 20 June 2016
CrossMark

To cite: Bailey DL, Lee $A$, Li BT, et al. BMJ Case Rep Published online: [please include Day Month Year] doi:10.1136/bcr-2016215645

\section{DESCRIPTION}

A 74-year-old man with metastatic gastro-oesophageal adenocarcinoma involving coeliac lymph nodes and liver was treated with fluorouracil and oxaliplatin (FOLFOX) chemotherapy. Despite initial good response, Oxaliplatin was omitted after development of significant peripheral neuropathy. His subsequent imaging showed progression of disease, predominantly in the liver. Selective internal radionuclide therapy (SIRT-Yttrium-90 $\left({ }^{90} \mathrm{Y}\right)$ resin microsphere radioembolisation) was chosen by the multidisciplinary team as the modality to target his dominant left hepatic lobar disease.

${ }^{90} \mathrm{Y}$ is a $\beta$-particle emitter suitable for radionuclide therapy, which, until recently, was not thought to be able to provide images directly from the decay of the radionuclide. ${ }^{1}$ Pretreatment $\left({ }^{18} \mathrm{~F}\right)$ fludeoxyglucose positron emission tomography (FDG PET)/CT demonstrated increased glucose metabolism in the rim of the large left lobe lesion. After informed consent, $810 \mathrm{MBq}\left({ }^{90} \mathrm{Y}\right)$-microspheres were injected into the left hepatic artery, using selective catheterisation. Approximately 18 hours postradioembolisation a ${ }^{90} \mathrm{Y}$ PET/CT scan confirmed good deposition of the radiolabelled microspheres around the lesion from which the dose of radiation could be derived. Follow-up $\left({ }^{18} \mathrm{~F}\right)$-FDG PET/CT scan taken 11 weeks after the intervention demonstrated a very good response with markedly reduced metabolic activity (figure 1). There was no progression of the left lobe lesion for 15 months.

The high sensitivity PET/CT scanner used allows acquisition of $\left({ }^{18} \mathrm{~F}\right)$-FDG and the technically challenging ${ }^{90} \mathrm{Y}$ images. ${ }^{90} \mathrm{Y}$ images are more difficult to capture due to very low radiation flux available for imaging from ${ }^{90} \mathrm{Y}$ decay $(32 \mathrm{ppm})$; this has been demonstrated previously. ${ }^{2}$ Liver directed SIRT is an emerging new treatment modality for patients with metastatic gastrointestinal cancers, which was recently shown to delay disease progression in the liver. ${ }^{3}$ Here we have shown that multitracer PET allows accurate dosimetry and therapeutic monitoring in a single imaging platform, and should be considered in future investigations of this treatment.

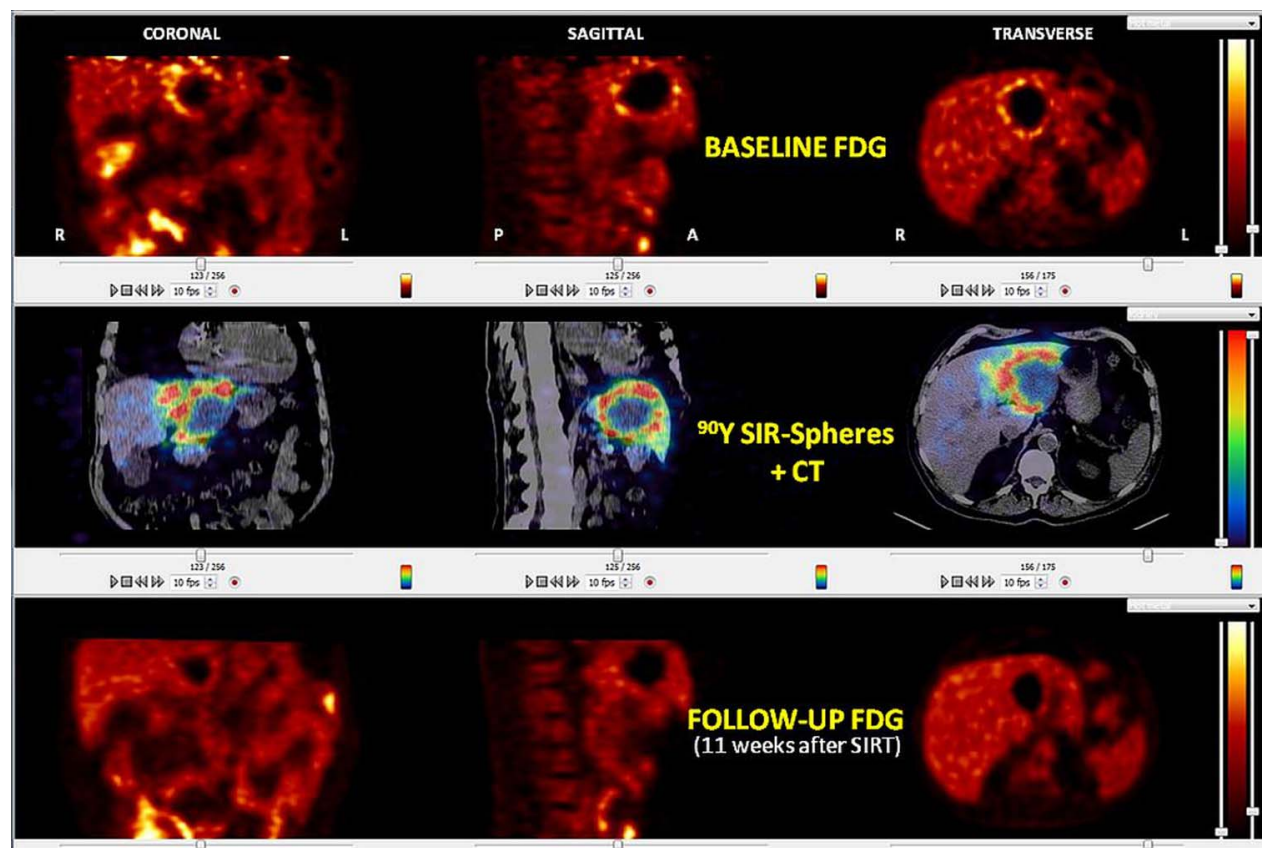

Figure 1 The figure demonstrating coronal, sagittal and transverse/axial sections in the three columns from left to right, respectively. The top row showing the pretreatment FDG-positron emission tomography (PET) scan at baseline. The middle rows showing the immediate PET/CT scan after insertion of ${ }^{90} \mathrm{Y}$ SIR-spheres. The bottom row demonstrating the follow-up FDG-PET scan at 11 weeks postprocedure, with markedly reduced metabolic activity around the left lobar lesion. FDG, fludeoxyglucose $\left({ }^{18} \mathrm{~F}\right) ;{ }^{90} \mathrm{Y}$ SIR-Spheres, Yttrium-90 selective internal radionuclide-spheres; SIRT, selective internal radionuclide therapy. 


\section{Learning points}

- High sensitivity positron emission tomography/CT scanners can acquire standard $\left({ }^{18} \mathrm{~F}\right)$-fludeoxyglucose and Yttrium-90 $\left({ }^{90} \mathrm{Y}\right)$ images to accurately record dose delivery and treatment response following selective internal radionuclide therapy.

- Durable response was achieved with $\left({ }^{90} \mathrm{Y}\right)$-microsphere radionuclide therapy in liver metastasis arising from gastro-oesophageal adenocarcinoma-a therapeutic option for isolated liver metastasis in patients who are otherwise unsuitable for aggressive surgical intervention.

Contributors DB contributed to the development of the initial manuscript drafts and acquisition of de-identified images for the case. AL and BTL contributed to manuscript reviews and final preparations. SC provided overall supervision of the manuscript design and final approval.

Funding BTL is supported by a Cancer Centre Core Grant (P30 CA008748) at Memorial Sloan Kettering Cancer Center, from the National Institutes of Health, USA.

Competing interests None declared.

Provenance and peer review Not commissioned; externally peer reviewed.

\section{REFERENCES}

1 Lhommel R, Goffette P, Van den Eynde M, et al. Yttrium-90 TOF PET scan demonstrates high-resolution biodistribution after liver SIRT. Eur J Nucl Med Mol Imaging 2009;36:1696.

2 D'Arienzo M, Chiaramida P, Chiacchiararelli L, et al. 90Y PET-based dosimetry after selective internal radiotherapy treatments. Nucl Med Commun 2012;33:633-40.

3 van Hazel GA, Heinemann V, Sharma NK, et al. SIRFLOX: randomized phase III trial comparing first-line mFOLFOX6 (plus or minus bevacizumab) versus mFOLFOX6 (plus or minus bevacizumab) plus selective internal radiation therapy in patients with metastatic colorectal cancer. J Clin Oncol 2016;34:1723-31.

Copyright 2016 BMJ Publishing Group. All rights reserved. For permission to reuse any of this content visit

http://group.bmj.com/group/rights-licensing/permissions.

BMJ Case Report Fellows may re-use this article for personal use and teaching without any further permission.

Become a Fellow of BMJ Case Reports today and you can:

- Submit as many cases as you like

- Enjoy fast sympathetic peer review and rapid publication of accepted articles

- Access all the published articles

- Re-use any of the published material for personal use and teaching without further permission

For information on Institutional Fellowships contact consortiasales@bmjgroup.com

Visit casereports.bmj.com for more articles like this and to become a Fellow 